\title{
A Capstone Course Targeting Industry Transition
}

\author{
G. E. Crain and M. P. Tull \\ School of Electrical and Computer Engineering \\ University of Oklahoma
}

\begin{abstract}
The capstone program for the School of Electrical and Computer Engineering (ECE) at OU simulates the experiences anticipated in the first two years of an industry assignment. Students are presented with an industry supplied problem, and given the resources and mentoring to develop a solution based on the individual team-members' educational experience as an Electrical or Computer Engineer. Many young graduates are confronted with the difficult tasks of learning the design process of their new employer, while trying to adapt to a new set of business priorities and metrics not associated with their educational experience. This course is designed to place them in a position of design responsibility on a multi-talented team, while they direct a project from the point of establishing a comprehensive requirement to demonstration of a product. In a single semester, they are exposed to targeted research, project budgeting and scheduling, formal oral reviews, design audits, documentation processes and team organization. Industry sponsorship provides a meaningful use for the student product, budgets to allow creative solutions to be implemented, and direct student supervision by practicing engineers. This course plays a significant role in the assessment of the educational effectiveness of the ECE BS programs. Students in this course are expected to understand the design process to the stage that they are ready to formulate not only the answers, but to define a well considered approach to an open ended, constrained design question. The ECE capstone course has evolved over the past 8years with significant input from the industrial sponsors and the multi-disciplinary lecturers who provide the materials and assess the progress of the students. The authors have been associated with the program from its onset. This paper describes the objectives for the course and the strategic use of industry sponsored design in the course implementation.
\end{abstract}

\section{A. Introduction:}

The Capstone experience is an ideal opportunity for Seniors to apply their design skill and to learn management skills with which to control the design ${ }^{1,2,3}$. The learning experience has been shown to be multiplied by exercising creative alternatives in a structured environment ${ }^{4,5}$. The School of Electrical and Computer Engineering (ECE) at the University of Oklahoma (OU) uses a process to help transition their design perspective from an answer-driven arena to a creative, needs-based, project environment. Industry sponsorship of Capstone projects provides a unique opportunity for students to begin working under practicing engineers. We impose design management processes that simulate an industry setting and which concurrently drive the design and the project schedule. Soft skills are developed through classroom lectures, given by outside experts, as well as through required assignments. This format also contributes to emphasizing the importance of ABET a-k topics ${ }^{6,7}$. Introduction to the concepts that documentation and design audits are an integral part of the design process is tacit to this course. Performance of the 
students in this course plays a major role in the assessment of our program's effectiveness to teach design fundamentals. This paper will introduce the process for this course and the tools used to structure a creative and responsive design environment to meet the objectives of the course.

\section{B. Course Objectives:}

The objectives of this course are focused on transitioning the student from an environment of problem solving only to one in which identifying and creating solutions to undefined problems can be affected. The objectives articulated in the class syllabus are:

- To provide an experiential learning activity for Senior Level Students in ECE and multidisciplinary projects.

- To simulate the environment of a professional engineering assignment by imposing design process controls, documentation requirements and team responsibilities

- To provide instruction in professional skills of design, program management, communications and other career topics not in the conventional curriculum

- To provide a measure of the student's educational readiness and understanding; knowledge of product technology required to meet the customer's performance requirements and constraints; understanding of requirements for written technical reports; ability to communicate their design including use of oral reports

Industry sponsored projects are solicited that fit within the scope of a 1-semester experience and have a product output of clear value to the sponsor. Sponsors are required to supply only three things: a 1-page Statement of Need; a Mentor who will work with the students to refine the design requirements and assess their solution, and a budget sufficient to cover the development and documentation of the product. The role of the Mentor provides two key elements to our process. The Mentor provides a customer metric for meeting market needs, and provides the students an opportunity to work under the guidance of a practicing engineer. Mentor supervision is loosely coupled since the teams are set-up to manage themselves; however, this often represents the first time many of our students have had the opportunity to work with or interface with the industry environment. Faculty and Mentors actively participate in all design reviews.

\section{Course Construct:}

This 1-semester, 3-credit hour course Capstone course takes the students thru a set of design milestones they would normally encounter in a rigorous 2 -year project in industry. The objective is not to develop complex products, but rather to introduce the multi-dimensional processes by which a creative design can be guided and controlled. Lectures are given once a week on topics that cover the soft skills necessary to operate effectively in a project environment. Reviews are structured using industry-like milestones that progress from validation of the requirement, through research, development, testing and demonstration. Documentation is a continuous process which culminates in a Final Report that withstands the scrutiny of technical writing experts.

C1: Project Selection. Students are assigned to projects in a competitive Job-Fair environment. In the first class meeting, they are provided with a synopsis of the spectrum of projects available and the individual project Statements of Need. They apply for the job by providing a resume and cover letter stating their top three project choices. Two design teams of nominally 4-persons are 
assigned to each project. Staffing is set by the Instructor. Very seldom is a student given their third choice project. Teams of 3 and 5 have been used, but these are used minimally and only on projects that are not expected to overburden or suppress individual contributions.

C2: An industry-like review process is used to assure the design addresses the customer need and offers an opportunity to develop and demonstrate the students' presentation skills. Table 1 outlines the requirements for the technical reviews during the semester, and points out opportunities to develop/assess soft skills of the students with these tools. Grading is based primarily on the students' articulation of the design and management of the project rather than on the product's ability to meet a list of specifications. The management process learned in this class drives most designs to a point that meets the basic requirement. Learning that process is the focus of this course.

Table 1. Technical Design Review Strategy

\begin{tabular}{|c|c|c|}
\hline Review (schedule) & Technical Requirement & Skill Development \\
\hline $\begin{array}{l}\text { Preliminary Design } \\
\text { Review } \\
\text { (Week 5) }\end{array}$ & $\begin{array}{l}\text { 1.Restate the requirement in dialog } \\
\text { with the customer } \\
\text { 2. Present the overall approach to } \\
\text { the task with a functional block } \\
\text { diagram } \\
\text { 3. Present schedule and budgets for } \\
\text { approval } \\
\text { 4. Project Organization }\end{array}$ & $\begin{array}{l}\text { 1. Oral presentation skills } \\
\text { 2. Organization of a } \\
\text { presentation } \\
\text { 3. Researching alternatives } \\
\text { 4. Investigation of the Need } \\
\text { 5. Understanding of team } \\
\text { member strengths }\end{array}$ \\
\hline $\begin{array}{l}\text { Critical Design } \\
\text { Review } \\
\text { (Week 9) }\end{array}$ & $\begin{array}{l}\text { 1. Restate the requirements } \\
\text { 2. Review top level functional } \\
\text { block diagram } \\
\text { 3. Introduce second and/or third } \\
\text { tier block diagrams } \\
\text { 4. Identify and specify interfaces } \\
\text { between functions } \\
\text { 5. Agreement on final features and } \\
\text { functions } \\
\text { 6. Release for Purchase }\end{array}$ & $\begin{array}{l}\text { 1. Designing to the } \\
\text { strengths of the team } \\
\text { 2. Distribution of design } \\
\text { responsibilities } \\
\text { 3. Articulation of the design }\end{array}$ \\
\hline $\begin{array}{l}\text { Final Demonstration } \\
\text { (Week 15) }\end{array}$ & $\begin{array}{l}\text { 1. Restate the requirements } \\
\text { 2. Design highlights } \\
\text { 3. Schedule variance } \\
\text { 4. Performance to budget } \\
\text { 5. Test of the product }\end{array}$ & $\begin{array}{l}\text { 1. Presentation Skills } \\
\text { 2. Dialogue with a spectrum } \\
\text { of end users } \\
\text { 3. Product integration and } \\
\text { validation }\end{array}$ \\
\hline
\end{tabular}

The Preliminary Design Review (PDR), held in the $5^{\text {th }}$ week, is a formal dialogue with the customer and the faculty and is used to establish the basic approach to the problem. It is graded on the basis of the comportment of the presentations. The Critical Design Review (CDR) is nominally held in the $9^{\text {th }}$ week. The CDR is an ungraded audit of the top-down functional design. The CDR is held in a round-table format with the mentors and faculty advisors. Teams 
explain the parsing of their design into major sub-functions with block diagrams and interface documents. The objective of CDR is to agree on features and functions of the final product and to affect any changes from the PDR design objective. The final review is an opportunity to showcase the design to the customer, usually at the sponsor's site. The presentation segment is set to provide not only design highlights, but to reflect on the lessons learned in project management (schedule, cost and critical performance parameters.) Grading of the final demo is on the presentation and on keeping the design focused on the requirement. Having a product that is fully compliant on that day is a key objective, but it is not a driving requirement for determining the grade in the course.

C3: Lectures are provided by appropriate experts on a just-in-time basis. Introducing the student to resources they have considered to be outside their purview helps broaden their perspective on the design process. In order to customize their design to customer needs, they must be able to hear those needs, to communicate their intent, and articulate the product in a way that meets customer expectations. Oral and written communications are key elements in securing work and establishing satisfactory completion of the project. Table 2 lists key external speakers who have an impact on grading student performance and submittals. These lectures are timed to have direct influence on scheduled, graded activities. Ph.D. students from the school of Technical Writing and from the Communications Department work with our students in preparing for various submittals and for grading those products. Ph.D. students and/or Faculty from the School of Business provide an experience in team building early in the program to help establish an understanding the need for and means for good group dynamics. Outside lecturers also provide perspective on Professional Registration, Design for Quality, Ethics in Industry, and Intellectual Property.

Table 2: Presentations and Grading (*) by External Lecturers

\begin{tabular}{|l|l|l|}
\hline \multicolumn{1}{|c|}{ Expert Lecturer } & \multicolumn{1}{c|}{ Lecture Content } & \multicolumn{1}{c|}{ Target Submittal } \\
\hline Student Placement Office & Resume Writing & Project Placement (4-days) \\
\hline Industry Mentors & $\begin{array}{l}\text { a. Project Kick-off } \\
\text { b. Meetings \& e-mails }\end{array}$ & $\begin{array}{l}\text { a. PDR* in 4 weeks, } \\
\text { b. CDR, Final Demo* }\end{array}$ \\
\hline School of Business Mgmt & Team Dynamics & Team Organization (4-days) \\
\hline $\begin{array}{l}\text { Communications } \\
\text { Department }\end{array}$ & $\begin{array}{l}\text { a. Oral Presentations and } \\
\text { b. PDR Dry Run with each } \\
\text { team }\end{array}$ & $\begin{array}{l}\text { a. PDR* (7-10 days) and } \\
\text { b. Final Demo* (9-weeks) }\end{array}$ \\
\hline English Department & $\begin{array}{l}\text { a. Technical Writing Lecture } \\
\text { b. Grading the DDD }\end{array}$ & $\begin{array}{l}\text { a. DDD* (3-weeks) and } \\
\text { b. Final Report (3-weeks) }\end{array}$ \\
\hline
\end{tabular}

C4: Students are responsible for defining all aspects of the design. Students are responsible for organizing their team in a way to define, affect, document and manage their project. Their final product consists not only of the target hardware/software entity, but also includes the entire process of developing and documenting this body of work. Generally, two competitive teams are assigned to each project. Each team is free to pursue a design solution that is best suited for implementation by the persons that comprise their team. The project requirements and needs are emphasized at the various reviews, but the solution is ultimately determined by the team. The design is kept on pace by the milestones established by the required submittals. 
Teams are required to first organize themselves for matrix responsibilities to cover the administration of the design. They are required to assign the jobs of Project Manager, Configuration Manager, Communications Officer, and Financial Officer to various individuals. The leadership responsibilities of each of these jobs assignments in affecting team meetings and in preparation of various submittals are prescribed, but participation by all team members is required in all major activities. Division of the technical design responsibilities is left to the team. However, this division of labor (in the form of a Work Breakdown Structure) is revealed and discussed at each review and in the Final Report. Team members assess their peers' performance in their respective contributions to the successful management of the team at the time of PDR and at the conclusion of the project.

C5: Documentation keeps the design on track. All aspects of the Design are documented in a series of submittals over the course of the semester. The approach is shaped by the Team's definition of a detailed schedule, a functional block diagram, a work breakdown structure (individual assignments to each scheduled task) and a project budget. These elements are all in place by the time of PDR. Team activities are monitored by the Mentors and the Instructor via Weekly Activity Reports and thru email or additional meetings as required. There are normally no great surprises at the reviews because of the frequency of interaction demanded by the course plan.

Major elements of the design are subject to several opportunities for review and revision in the course of the semester. For instance, the Schedules and Budgets are reviewed by the instructor for comment prior to being presented to the customer at PDR. The baseline approach is critiqued at PDR so that the design can progress to the next-level down in time for the CDR. Then, at CDR, the features and functions of the final design are reviewed and agreed upon before circuit designs are detailed or parts are fabricated. Certain critical components may be fabricated before either of these reviews to avoid critical timeline problems. However, the majority of the product development, integration and testing activities are relegated to the time following CDR so that the needs and divisions of the work are clearly understood.

Development of the Final Report is a 4-step process. The Design Description Document (DDD) formally documents the state of the design at PDR (subject to modifications from that design). This document is a draft of the first 4-chapters of the Final Report. The Chapter outline requirements for the DDD are defined by the Syllabus. The students are required to provide an extended outline for this document at the sub-chapter level. The instructor provides comments to this approach before writing of the document begins. The Technical Writing expert grades the DDD and the Instructor and the Mentor provide technical comments suggesting areas for improvement. The grade on the final report is heavily influenced by the team's response to the Tech Writer's criticisms and to the team's demonstrated ability to carry those changes forward into the three new chapters required in the final report.

A sequence of scheduled submittals is used to cause the students to look at various aspects of the design. These include the key components of performance, schedule and cost. They are coached to organize the team to perform basic management functions in preparation for the assigned task of subdividing the work of designing and building the product. Reports on the Progress, Plans 
and Problems of the team are provided to the Mentor and the Instructor to monitor progress and to alert them to special needs of the team. The CDR is a clear line of demarcation between defining the design and fabricating the product. The students' appreciation for the Design and the Process is strengthened by documentation in the Design Description Document (DDD) and revisited in the writing of the Final Report. The Final Demonstration is a key opportunity for verbal feedback on the quality of their work by industry representatives, Faculty assessors and perhaps most importantly, their teammates.

Table 3: Formal Submissions Required for Each Team

\begin{tabular}{|c|c|c|}
\hline Week & Document & Function \\
\hline 1 & Resume & $\begin{array}{l}\text { Individual Skills information to } \\
\text { Instructor, Team and Mentor }\end{array}$ \\
\hline 2 & Team Organization & Matrix Jobs \\
\hline $3-16$ & $\begin{array}{l}\text { Weekly Activity Reports } \\
\text { (WARs) }\end{array}$ & $\begin{array}{l}\text { Progress, Plans and Problems } \\
\text { To Mentor \& Faculty weekly }\end{array}$ \\
\hline 3 & Schedules & Basic list of tasks \\
\hline 4 & Budgets & Labor and Materials \\
\hline 6 & Preliminary Design Review & $\begin{array}{l}\text { Articulation of the Requirement } \\
\text { Functional Block Diagram } \\
\text { Work Breakdown Structure } \\
\text { Lab Notebooks (first time) } \\
\text { Peer Assessments }\end{array}$ \\
\hline 7 & PDR Action Items & $\begin{array}{l}\text { List of Actions resulting from } \\
\text { review of the PDR videotapes }\end{array}$ \\
\hline 8 & $\begin{array}{l}\text { Design Description } \\
\text { Document (DDD) Outline }\end{array}$ & $\begin{array}{l}\text { Thematic Sentences } \\
\text { Figure and Table List } \\
\text { Page Budgets } \\
\text { Writing Assignments }\end{array}$ \\
\hline 9 & Critical Design Review & $\begin{array}{l}\text { Detailed Block Diagrams } \\
\text { Functional Interface Specs }\end{array}$ \\
\hline 11 & Design Description Doc & First 4 chapters of the final report \\
\hline 12 & Test Requirements Doc & $\begin{array}{l}\text { Demonstration Format } \\
\text { Key Parameters to be met }\end{array}$ \\
\hline 15 & Final Demo \& Lab Books & $\begin{array}{l}\text { Product Delivery } \\
\text { Lab Book Review } \\
\text { Final Peer Assessments }\end{array}$ \\
\hline 15 & Final Report & Product Documentation \\
\hline
\end{tabular}

D. Experience with the Program: This class is offered in both the Spring and Fall semesters. Nominal class size is 45 to 50, with as few as 35 and as many as 67. Project Sponsors have included major commercial companies, government agencies, start-up companies and a few faculty members. Most sponsors have returned for at least a second semester to offer a new or refined project. Some of our larger customers have even sponsored multiple projects in a single semester. The fact that we have two teams on each project gives the project a high probability of at least one working solution at the end of the semester. It gives us great delight when a 
customer is vexed with the problem of finding a way to integrate the best features of the two competitive solutions into a common product. Many of our students have been hired directly out of these projects and a significantly higher number have received offers that weren't taken.

Sponsors for six- to-eight projects must be secured every semester. Most are in Oklahoma, but several from Texas and Arkansas have been included on a regular basis. Mentors must be on site three-times during the semester, but they are expected to keep in regular contact with the students to keep the project on track. Enrolling both Mentors and Students on our web courseware has somewhat eased the remote communications problem. Students generally make at least one visit to the sponsoring agency, and final demonstrations are usually made at the customer's site. Our rule of thumb for defining projects is that students should not be in the direct line with product time to market. Projects that develop products that lead to greater efficiency, improved performance, or demonstrate critical or new functionalities are preferred.

Projects generally can be executed by a mix of students from our Electrical and Computer Engineering programs. However, we have agreements with the Mechanical, Civil and Industrial Engineering Departments that allow us to exchange students between our capstones to staff and support Multi-disciplinary Project opportunities. The types of projects range from

- Software Development

- Develop a data-base tool to catalogue and analyze traffic parameters for a multicounty area

- Develop a Visual Basic tool that will route the pin interconnects for a specific set of IC's directly from the Matlab simulation script

- Develop a PDA-based interface for real-time, wireless linkage of production floor data with global inventory and tracking databases

- Hardware Control

- Develop LabView Script to automatically control and operate a test facility for a prescribed set of Unit Tests.

- Develop and integrate software to provide variable parameter test controls to support a family of electric motors

- Hybrid Systems

- Develop Circuit Boards and Software to provide web-based control for Highway Monitoring Components (Cameras, Signage, Traffic Counters)

- Develop circuit boards to code and digitally record multi-channel MPEG audio and then remotely play audio segments in prescribed order at set times.

- Multi-Disciplinary Systems

○ Develop a system to hermetically destroy the needles from spent syringes with no requirement for alignment by humans.

- Develop an electro-mechanical tamping system to vary the compression rate of a full sized steam-roller

- Develop mechanical fixtures and control software for preparation of prescriptions with varying dosages on a robotic table.

These are some of the challenging projects we've undertaken during the near decade over which this class was developed. Many of these were very successful in a single semester. On the other hand, many others developed into a 2-to3-semester sequence of projects with increasing levels of definition, constraints, and performance improvement. Since our main focus is to have the 
students understand and experience the complete development process, we generally produce both happy customers and successful students.

Products from our student projects can be found in place today in a number of factories: on the production floor, in the labs and on PC's in engineering offices. Derivative hardware is at work on a number of radar towers across the US and along Oklahoma highways. Hardware and software functionalities demonstrated by our students have made an impact on the competitiveness and ability to acquire funding for a number of inventors and small businesses within our state. Most importantly, our students were able to see application of their skills to the creation of solutions for a real need.

Overall the students have been very satisfied with the course. This satisfaction is tempered by the vagaries of design success, Mentor leadership, and team compatibility. We solicit a great deal of feedback from the students in this course. Changes were made to the course material in response to their suggestions. The nature of the outcomes of this course as it is used in assessing our degree programs is reserved for another publication.

E. Conclusions: We have strived to develop a Capstone Experience that will expose the students to the full dimensionality of Designing to a Need. They are required to refine and revisit the project requirements throughout the semester. Submittals are staged in a way that students clearly understand the relationship between performance, cost, and schedule under the constraints set by the customer. The "customer" is a composite of the industry Mentor for performance and cost and the Faculty Instructor for schedule and documentation. The students are given the tools to manage a small to mid-sized project and the opportunity to apply these to a product that matches their skill and interest. Having this experience in an academic environment allows them to focus on learning the process. We believe that the application of this process can and will be extended to many tasks our graduates will face throughout their careers.

[1] Ruud, C.O., Deleveaux, V.J., "Developing and Conducting an Industry Based Capstone Design Course" Frontiers in Education Conference, 1997, 27th Annual Conference, 'Teaching and Learning in an Era of Change', vol.: 2, 644-647, Nov. 5-8, 1997.

[2] Parker, J., Midkiff, C., Kavanaugh, S., "Capstone Senior Design at the University of Alabama", Frontiers in Education Conference, 1996. FIE '96. 26th Annual Conference, vol.: 1, 258-262. Nov. 16-9, 1996.

[3] Heitman, G.K., Manseur, R., Organization of a Capstone Design Course, Frontiers in Education Conference, 2000. FIE 2000. 30th Annual, vol.: 1, F1C/1-F1C/5, Oct. $18-21,2000$.

[4] Masi, J.V., "Teaching the Process of Creativity in the Engineering Classroom", Frontiers in Education Conference, 1989, 288-292, Oct. 15-17,1989.

[5] Rover, D.T., "Perspectives on Learning in a Capstone Design Course", Frontiers in Education Conference 2000, FIE 2000, vol.: 2, F4C/14 - F4C/19, Oct. 18-21, 2000. 
[6] Bond, B., "The Difficult Part of Capstone Design Courses", Frontiers in Education Conference, 1995, vol: 1, 2c3.1-2c3.4, Nov. 1-4, 1995.

[7] Mertz, R.L., "A Capstone Design Course [Electrical Engineering]", IEEE Trans. On Education, vol.: 40, no.: 1, 41-45, Feb. 1997.

Jerry Crain has served as Director and Interim Director of Electrical and Computer Engineering since 1995. He came to OU as a Texas Instruments Professor in 1994 after 24 years in Advanced Radar at TI. His research interests are in Phased Array Radar, Antennas and Microwaves. BSEE Wichita University, MSEE and PhDEE University of Colorado.

Monte Tull joined Electrical and Computer Engineering at OU in 1996 after a 29-year career in advanced switching technology at AT\&T, Bell Labs, and Lucent Technologies. Research interests are in digital hardware, multiple-valued logic, reconfigurable computing, and embedded systems. BS Physics, East Central State University; MSIE, OU; MSEE, OSU; PhDEE, OU. 